\title{
ANALISIS VARIASI JUMLAH SUDU BERENGSEL TERHADAP UNJUK KERJA TURBIN CROSS FLOW ZERO HEAD
}

\author{
Yesung Allo Padang, I Dewa Ketut Okariawan dan Mundara Wati \\ Jurusan Teknik Mesin Fakultas Teknik, Universitas Mataram, \\ Jl. Majapahit 62 Mataram 83125 \\ e-mail: yesungallopadang@gmail.com
}

\begin{abstract}
ABSTRAK
Pembangkit Listrik Tenaga Mikro Hidro (PLTMH) adalah pembangkit energi yang mengkonversi energi air hingga menjadi energi listrik pada kapasitas kecil. Dengan mengembangkan PLTMH berarti turut mengembangkan sumber energi terbarukan yang tidak merusak lingkungan alam sekitar. Pada penelitian ini turbin cross flow berada pada posisi terendam dalam air sehingga dikatakan turbin cross flow zero head. Tujuan dari penelitian ini adalah untuk menganalisa unjuk kerja turbin cross flow zero head. Parameter yang divariasikan adalah jumlah sudu (12, 6 dan 4 sudu) dan pergerakan sudu (sudu berengsel dan sudu tetap). Unjuk kerja turbin yang dianalisa adalah efisiensi sistem, energi output dan putaran generator. Hasil penelitian menunjukkan bahwa unjuk kerja turbin terbaik diperoleh saat jumlah sudu 12 dengan gerakan sudu tetap. Efisiensi sistem yang terbaik sebesar $0,47 \%$ diperoleh pada kecepatan putar generator sebesar 89,9 rpm dan energi output generator sebesar 29,25 Watt.
\end{abstract}

Kata kunci : Turbin Cross Flow, Zero Head, Sudu Berengsel.

\begin{abstract}
Micro Hydro Powewr Plant (MHPP) is a power plant that converts water energy into electrical in a small capacity. Developing MHPP means developing renewable energy which is environmentally save. In this researh the position of cross flow turbine is submerged in water so it is said cross flow zero head turbine. The purpose of this reserch is to analyze the performances of cross flow zero head turbne. The variation parameters include number of blade (12, 6 and 4 blades), fixed blades and sliding blades (unbolted blades). The turbine performances to be analyzed are system efficiency, turbine output power and generator speed. The results show that the best turbine performance is obtained when number of blades is 12 with fixed blade. This yields to the best system efficiency of $0.47 \%$ obtained at generator speed of 89.9 rpm and generator power output of 29.25 Watts.
\end{abstract}

Keyword: Cross Flow Turbine, Zero Head, Sliding Blades.

\section{PENDAHULUAN}

Energi adalah kemampuan untuk melakukan kerja (energy is the capacity for doing work). Berdasarkan sumbernya, energi terbagi dua yaitu energi yang berasal dari bumi (terrestrial) dan energi yang berasal dari luar bumi (extra terrestria). Sumber energi yang berasal dari bumi dikategorikan sebagai jenis energi yang dapat didaur ulang (renewable energy).

Energi air merupakan salah satu energi yang termasuk ke sumber energi dari alam dan bersifat sebagai renewable energy. Energi air dapat dimanfaatkan untuk meningkatkan dan mengembangkan pembangkit energi listrik. Sehingga, pembangkit energi listrik memiliki tambahan stok energi listrik yang akan disaluran ke konsumen.

Pembangkit Listrik Tenaga Mikro Hidro (PLTMH) merupakan salah satu pembangkit listrik yang memanfaatkan energi air sebagai penggerak turbin. Energi kinetik air dirubah atau ditransmisikan menjadi energi mekanik di dalam turbin, karena air memutar sudu turbin [1]. Energi mekanik yang dihasilkan kemudian diubah menjadi energi listrik melalui generator [2].

Selama ini energi air yang digunakan adalah air dengan ketinggian dan debit yang besar. Sementara energi air dengan ketinggian dan debit yang kecil, belum banyak dimanfaatkan. Padahal di beberapa wilayah Indonesia memiliki potensi yang 
cukup besar untuk dikembangkan menjadi pembangkit listrik meski tinggi jatuh air (head) dan debit yang kecil (microhydro).

Bentuk turbin yang tepat digunakan pada Pembangkit Listrik Mikro Hidro adalah turbin cross flow. Daya guna kincir air dari jenis yang paling ungggul mencapai $70 \%$, sedangkan efisiensi turbin cross flow mencapai 82\% [3]. Selain itu diperlukan kajian khususnya untuk turbin dengan komponen penggerak (runner) yang terdiri dari sudu - sudu yang mengelilinginya.

Sudu yang mengelilingi runner berfungsi sebagai penangkap energi kinetik inlet air yang menabrak permukaan sudu sehingga menyebabkan runner mentransmisi energi kinetik inlet air tersebut menjadi energi mekanik pada rotor turbin. Kemudian energi mekanik yang diperoleh tersebut akan ditransmisi menjadi energi listrik oleh generator.

Generator pada instalasi turbin yang digunakan pada penelitian ini adalah generator arus Alternating Current (AC). Generator arus AC berfungsi sebagai pengubah energi mekanik menjadi energi listrik arus bolak balik. Generator AC dapat juga dikatakan generator sinkron karena jumlah putaran rotornya sama dengan jumlah putaran medan magnet pada statornya.

Adapun tujuan dari penelitian ini adalah untuk menganalisa unjuk kerja turbin cross flow zero head. Dengan parameter yang divariasikan adalah jumlah sudu $(12,6$ dan 4 sudu) dan pergerakan sudu (sudu berengsel dan sudu tetap). Unjuk kerja turbin yang akan dianalisa adalah efisiesi sistem, energi output dan putaran generator.

Manfaat penelitian ini adalah menambah wawasan dan pengetahuan tentang pengenmbangan teknologi Pembangki Listrik Tenaga Mikro Hidro (PLTMH) yang dapat dikembangkan dengan memanfaatkan energi air tanpa ketinggian jatuh air menabrak permukaan sudu turbin. Sehingga, PLTMH dapat dikembangkan dengan memanfaatkan aliran sungai biasa atau saluran irigasi yang sering digunakan untuk mengairi daerah persawahan.

\section{LANDASAN TEORI}

Penelitian dan aplikasi turbin cross-flow untuk pembangkit listrik tenaga mikrohidro telah dilakukan di Kalimantan Barat. Penelitian dilakukan pada beberapa sungai, antara lain; sungai Kamat, sungai Temiang, sungai Malam, sungai Mengirang, dan sungai Sintot. Metode yang digunakan pada penelitian ini adalah perhitungan dari data - data yang diperoleh saat penelitian di masingmasing sungai.

Daya desain dihitung dengan efisiensi turbin cross-flow sebesar 0,76, efisiensi generator 0,89 dan efisiensi transmisi mekanik 0,98. Efisiensi turbin dihitung dari data yang sesuai dengan head dan flow desain masing - masing sungai. Dalam penelitian ini referensi turbin cross-flow yang mengacu pada turbin Osberger-Jerman dan turbin cross-flow buatan Indonesia tipe T-14 D150 dan D300 [4].

Hasil penelitian menyatakan bahwa pemanfaatan turbin cross flow untuk potensi energi air yang tersedia di alam sekitar sangat cocok mengingat turbin impuls jenis cross flow memiliki karakteristik yang cocok untuk range head rendah hingga medium.

Tim peneliti dari Universitas Hasanuddin Makassar, telah melakukan penelitian tentang pembuatan dan pengujian pembangkit listrik tenaga mikrohidro turbin Banki daya 200 Watt [5]. Penelitian ini bertujuan untuk mengetahui cara yang digunakan untuk mendapatkan start dalam fabrikasi turbin Banki dari 200 Watt dengan kapasitas daya electrical, menentukan pengaruh pembukaan sudu tetap dan variasi dinamometer loading.Penelitian ini dilakukan dan diperiksa secara langsung di laboratorium Universitas Hasanudin, Makassar. Pengukuran kecepatan putar turbin, kapasitas air, dengan menggunakan tachometer tangan, dan manometer. Pembukaan sudu pengarah tetap dilakukan saat penelitian.

Hasil dari penelitian menunjukkan bahwa pada pembukaan sudu pengarah dengan variasi beban dan putaran yang konstan pada turbin menghasilkan daya listrik sebesar 72 Watt dengan efisiensi turbin mencapai $30,7 \%$ saat pembukaan sudu pangarah $12^{\circ}$ dengan beban $2 \mathrm{~kg}$ di putaran $550 \mathrm{rpm}$ dan daya maksimum sebesar 186 Watt dengan efisiensi turbin mencapai $78,9 \%$ saat pembukaan sudu pangarah $20^{\circ}$ dengan beban $5,2 \mathrm{~kg}$ di putaran $550 \mathrm{rpm}$.

Tim dari UIN Malang telah melakukan penelitian tentang pemodelan turbin 
cross flow untuk diaplikasikan pada sumber air dengan tinggi jatuh dan debit kecil. Variabel terikatnya adalah memvariasikan jumlah sudu yang berhubungan dengan jumlah putaran, daya turbin, dan efisiensi turbin. Selain itu, variasi juga dilakukan pada bentuk saluran yang digunakan yaitu saluran terbuka berbentuk persegi, setengah lingkaran dan trapesium [6].

Penelitian dilakukan dengan mengambil beberapa input yang disesuaikan dengan kebanyakan yang ada di lapangan. Input yang digunakan adalah kecepatan alir, tinggi jatuh, kemiringan saluran, lebar penampang saluran, jari - jari saluran, diameter luar turbin dan lebar turbin. Sementara itu, besaran yang dibuat sebagai variabel adalah jumlah sudu pada turbin cross flow. Penampang sebagai saluran air yang dipakai berbentuk persegi, setengah lingkaran dan trapesium. Ketiganya dibuat terbuka.

Hasil penelitian menunjukkan bahwa dengan asumsi lebar penampang $4 \mathrm{~m}$, tinggi jatuh $2 \mathrm{~m}$, jari - jari $2 \mathrm{~m}$, kemiringan $1 / \sqrt{3}$ kecepatan aliran $2 \mathrm{~m} / \mathrm{s}$, diameter luar turbin $0,75 \mathrm{~m}$ dan lebar turbin 4,3 m, maka turbin dengan jumlah sudu 12 memiliki jumlah putaran, daya turbin dan efisiensi turbin yang paling besar. Bilamana jumlah sudu diperbanyak, maka jumlah putaran, daya turbin dan efisiensi turbin semakin kecil. Sementara itu, penelitian untuk menentukan jenis penampang saluran didapatkan bahwa jenis saluran dengan penampang trapesium dihasilkan jumlah putaran, daya turbin dan efisiensi turbin yang paling besar kemudian disusul dengan jenis penampang persegi dan terakhir adalah jenis penampang lingkaran.

Ada pula yang mengkaji kinerja turbin cross flow berbasis konstruksi silinder (drum) poros vertikal untuk potensi arus sungai. Tahap awal penelitian adalah menyiapkan konstruksi silinder berdiameter $1 \mathrm{~m}$ yang dibuat dari lembaran stainless steel ukuran $2 \mathrm{~mm}$ [7]. Selubung silinder dibelah menjadi empat bagian. Bagian-bagian selubung tersebut diputar dengan pusat sumbu adalah bagian tengah busur selubung sehingga silinder - silinder tersebut membentuk turbin cross flow. Pada bagian luar dipasang rumah turbin yang dilengkapi pengarah aliran menuju sudusudu turbin. Turbin cross flow dihubungkan dengan pompa sentrifugal (sebagai beban) melalui sistem transmisi poros dan roda gigi. Tahap selanjutnya adalah uji karakteristik turbin. Dalam uji ini dilakukan optimasi sudut sudu jalan turbin. Uji dilakukan di aliran sungai dengan parameter yang diukur adalah debit dan head aliran sungai untuk menghitung daya input turbin serta head dan debit aliran yang dihasilkan oleh pompa irigasi untuk menghitung daya output pompa.

Berdasarkan pada hasil pengujian, turbin aliran silang poros vertikal sebagai penggerak pompa air yang dibuat berdasarkan konstruksi silinder yang dibelah menjadi empat mempunyai sudut sudu jalan optimum $60^{\circ}$ dengan debit aliran masukan sebesar 0,23 $\mathrm{m}^{3} /$ det, debit aliran keluaran pompa sebesar $0,000253 \mathrm{~m}^{3} /$ det, daya hidrolis yang dihasilkan pompa sebesar 3,05 watt dan mempunyai efisiensi sistem sebesar $4,98 \%$.

\section{METODE PENELITIAN}

Penelitian ini dilakukan di laboratorium konversi energi di Universitas Mataram pada akhir bulan juli. Alat yang digunakan saat penelitian antara lain;

a. Stopwacth : digunakan untuk lama waktu debit air mencapai volum sebanyak 5 liter pada gelas ukur.

b. Gelas ukur : digunakan sebagai wadah penampung dan pengukur debit air hingga mencapai batas ukuran volum yang ditetapkan.

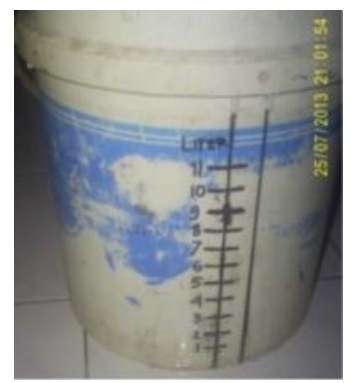

Gambar 1. Gelas ukur yang digunakan untuk mengukur volum debit air

c. Tachometer: digunakan untuk mengukur besar putaran generator turbin saat penelitian. 


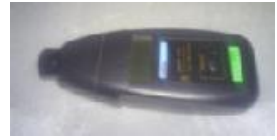

Gambar 2. Tachometer

d. AVOmeter : Untuk mengukur besar tegangan listrik (V) dan arus listrik (I) sebagai energi output generator berupa daya listrik.

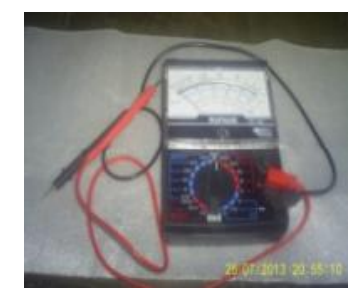

Gambar 3. AVOmeter

e. Meteran dan penggaris : untuk mengukur panjang atau jarak dari beberapa bagian atau komponen pada rangka instalasi turbin yang digunakan saat penelitian.

f. Ember atau bak penampung : digunakan untuk menampung air sebagai fluida kerja pada turbin yang dibuang setelah memutar atau menggerakkan rotor turbin. Ada di bagian bawah rangka instalasi turbin.

g. Instalasi turbin cross flow zero head:

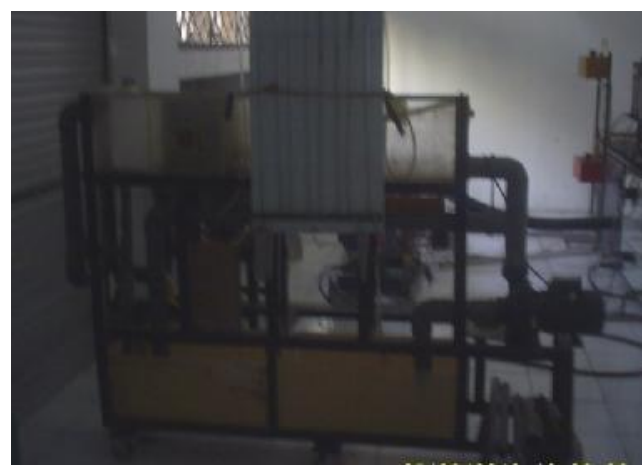

Gambar 4. Instalasi turbin yang digunakan untuk pengujian saat penelitian

Desain instalasi turbin di atas merupakan hasil karya dari beberapa dosen yang melakukan penelitian yang berhubungan dengan turbin cross flow zero head pula. Instalasi turbin diatas menggunakan pompa air sebagai pensirkulasi air dari bak penampung air di bagian bawah menuju penampungair yang menuju nosel. Sehingga, energi kinetik inlet air dapat memutar rotor turbin dan mengakibatkan terjadinya transmisi energi pada instalasi turbin tersebut. Energi output generator adalah berupa energi listrik atau daya listrik. Energi output generator merupakan salah satu unjuk kerja turbin yang akan dianalisa.

Terdapat rangkaian listrik yang akan dihubungkan dengan kabel pada generator turbin saat pengukuran tegangan listrik $(\mathrm{V})$ dan aliran arus listrik (I). Rangkaian listrik tersebut terdiri dari 20 buah lampu Ligh Emitting Diode (LED) dan masing -masing lampu berkapasitas 3 Watt.

Jumlah spool yang ada di dalam generator pada instalasi turbin adalah 6 buah dan pada masing - masing spool dililiti oleh kawat tembaga berdiameter $0,1 \mathrm{~mm}$ sebanyak 2500 lilitan.

\section{h. Tabung Pitot}

Untuk mengukur ketinggian relatif terhadap alran fluida inlet menuju permukaan sudu pada rotor dan fluida outlet menuju saluran pembuangan.

Variabel-variabel penelitian yang digunakan ada 2 varabel yaitu;

* Variabel terikat (dependent variables) adalah faktor - faktor yang diobservasi dan diukur untuk menentukan adanya pengaruh variabel bebas. Tujuan utama dari penelitian adalah menjelaskan variabel terikat. Dengan menganalisis variabel terikat, diharapkan dapat ditemukan jawaban atau penyelesaian masalah. Yang menjadi variabel terikat pada penelitian ini adalah analisa variasi jumlah sudu berengsel terhadap unjuk kerja turbin cross flow zero head. Unjuk kerja turbin yang dianalisa antara lain; efisiensi sistem, energi output dan putaran generator. Sehingga dapat mengembangkan PLTMH yang menggunakan saluran irigasi untuk pengairan di area persawahan yang aliran airnya mengalir secara mendatar tanpa adanya ketinggian jatuh air (zero head).

* Variabel bebas (independent variables) adalah variabel yang menyebabkan atau mempengaruhi variabel terikat. Adapun yang menjadi variabel bebas pada penelitian ini adalah jumlah sudu berengsel akan mempengaruhi unjuk kerja turbin. Semakin banyak jumlah sudu maka unjuk kerja turbin menjadi 
semakin baik. Perbandingan unjuk kerja turbin dengan sudu tetap atau tidak berengsel dengan sudu berengsel. Anggapan sementara, dengan menggunakan sudu berengsel akan mengurangi gaya seret (drag force) yang terjadi di bagian belakang sudu turbin sehingga unjuk kerja turbin menjadi lebih baik dengan menggunakan sudu berengsel.

Prosedur penelitian yang dilakukan untuk penelitian yaitu; persiapan alat - alat yang akan digunakan yang akan digunakan saat penelitian dan pengujian. Beberapa tahap pengujian yang dilakukan saat penelitian antara lain;

1. Bak penampung air yang ada di bagian bawah rangka turbin, diisi penuh.

2. Keran saluran pembuangan fluida kerja yang terhubung langsung dengan saluran yang mengalirkan air dari bak penampung bagian bawah instalasi turbin ditutup, agar tidak mengganggu proses pendorongan air ke kotak penampung air bagian atas instalasi turbin sehingga aliran air yang masuk ke turbin menjadi lambat dan rotor tidak berputar.

3. Kemudian pompa listrik dihidupkan.

4. Setelah pompa dihidupkan, pentil di ujung kotak penampung air bagian atas ditekan yang bertujuan untuk mengurangi gelembung udara di dalam bak penampung air bagian atas.

5. Air buangan yang keluar dari saluran pembuangan turbin, ditampung dengan gelas ukur (ember). Dikombinasikan dengan pengukuran lama waktu yang digunakan agar gelas ukur terpenuhi volumenya hingga 5 Watt, dengan menggunakan stopwatch.

6. Pencatatan data - data antara lain; putaran generator, tinggi air raksa pada tabung pitot, tegangan listrik dan arus listrik dengan parameter yang divariasikan saat penelitian adalah jumlah sudu (4, 6 dan 12 sudu) dan pergerakan sudu (sudu berengsel dan sudu tetap).

7. Pompa listrik dimatikan. Kemudian, pentil di ujung kotak penampung air bagian atas ditekan yang bertujuan untuk mengurangi gelembung udara di dalam bak penampung air bagian atas. Dan, keran saluran pembuangan air dari kotak penampung air bagian atas instalasi turbin dibuka. Agar air buangan di saluran pembuangan dapat keluar dengan baik dan tersalur langsung menuju bak penampung air bagian bawah instalasi turbin.

Rangkaian sudu turbin cross flow yang digunakan

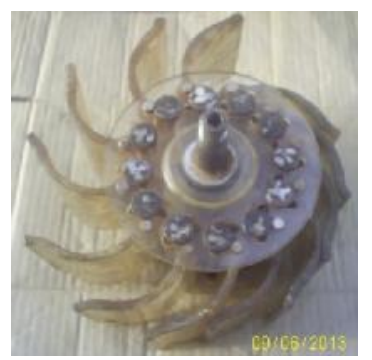

Gambar 5. Sudu yang digunakan saat pngujian

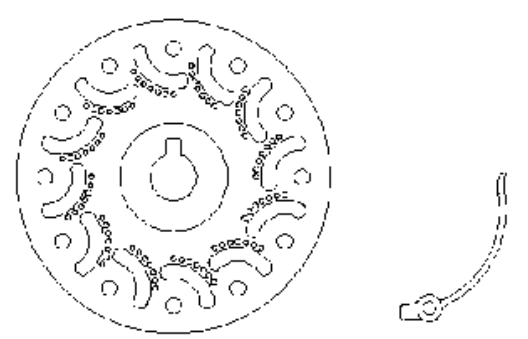

Gambar 6. Disk dan sudu turbin tampak depan

Langkah-langkah yang dilakukan saat pengujian:

1. Pembukaan disk turbin dilakukan pada disk yang kemunculan poros turbinnya pendek. Sebelum lempengan disk tersebut ditarik dari porosnya, dilakukan pelepasan baut pengunci engsel sudu.

2. Dilakukan pengambilan sudu satu per satu untuk menvariasikan jumlah sudu yang dipasang pada disk dengan posisi yang mengelilingi poros turbin (rotor).

3. Untuk memvariasikan gerakan engsel sudu tetap dan sudu berengsel, dilakukan pengencangan baut pengunci engsel sudu agar diperoleh gerakan sudu yang tetap.

\section{HASIL DAN PEMBAHASAN}

Berdasarkan parameter yang divariasikan pada penelitian ini, diperoleh data-data hasil penelitian berupa unjuk kerja turbun cross flow zero head. Unjuk kerja turbin yang dianalisa adalah efisiensi turbin, energi output dan putaran generator.

Alat ukur yang digunakan untuk mengukur putaran generator adalah tachometer. Cara penggunaan tachometer untuk mengukur 
putaran generator adalah dengan menyorotkan laser tachometer ke sebuah elemen berupa yang tempelan seperti plaster yang berbentuk kotak kecil yang berwarna putih dan diletakkan pada tempat yang reflektif di permukaan generator yang dapat dilihat langsung dari jarak jauh. Dengan adanya elemen tersebut, memberi tanda kecepatan putaran generator per menit. Karena, laser tachometer membaca kecepatan putaran sebuah benda yang berputar dengan adanya pantulan kembali sinar laser dari sebuah elemen berupa titik pantul sinar laser ke tachometer pada benda yang berputar.

Agar hasil pengukurannya permanent, maka penyorotan sinar laser harus tepat pada satu titik pusat penunjukan sinar laser ke titik pantul yang telah ditempelkan pada sebuah titik di permukaan generator yang berputar nantinya. Tanpa adanya geseran dan perpindahan penyorotan laser tachometer yang digenggam saat pengukuran putaran generator, selama 1 menit.

Hasil pengukuran putaran generator parameter yang divariasikan akan ditampilkan pada tabel 1, berikut ini.

Tabel 1. Putaran generator (rpm)

\begin{tabular}{|c|c|c|c|c|}
\hline \multicolumn{2}{|c|}{ Variasi } & \multicolumn{3}{c|}{ Jumlah sudu } \\
\cline { 2 - 5 } \multirow{2}{*}{$\begin{array}{c}\text { Sudu } \\
\text { Berengsel }\end{array}$} & $\begin{array}{c}\text { Diberi } \\
\text { beban }\end{array}$ & 68,7 & 56,3 & 39,1 \\
\cline { 2 - 5 } & $\begin{array}{c}\text { Tanpa } \\
\text { beban }\end{array}$ & 70,9 & 59,4 & 42,1 \\
\hline \multirow{2}{*}{$\begin{array}{c}\text { Sudu } \\
\text { Tetap }\end{array}$} & $\begin{array}{c}\text { Diberi } \\
\text { beban }\end{array}$ & 89,9 & 65,3 & 43,8 \\
\cline { 2 - 5 } & $\begin{array}{c}\text { Tanpab } \\
\text { eban }\end{array}$ & 91,5 & 68,7 & 50,6 \\
\hline
\end{tabular}

Tabel 1. menunjukkan bahwa parameter sudu teteap memiliki putaran generator yang lebih tinggi dibandingkan parameter sudu berengsel. Meski ditambah dengan memberikan variasi pembebanan. Yang dimaksud pembebanan disini adalah penyambungan energi output generator dengan rangkaian listrik yang ada di sisi rangka instalasi turbin yang sebelah kanan. Bila dilakukan pembanding berdasakan parameter tersebut, maka putaran generator akan selalu lebih besar saat generator tidak dihubungkan dengan rangkaian listrik (tanpa beban).

Berdasarkan parameter variasi jumlah sudu (12, 6 dan 4 sudu), 12 sudu adalah variasi jumlah sudu yang memiliki putaran generator yang paling tinggi. Jika dihubungkan dengan parameter pergerakan sudu (sudu berengsel dan sudu tetap), maka 12 sudu dengan gerakan sudu tetap adalah putaran generator tertinggi diantara parameter variasi jumlah sudu dengan pergerak sudu berengsel.

Berikut ini akan ditampilkan data-data pada tabel 1 dalam bentuk gambar grafik pada gambar 1 .

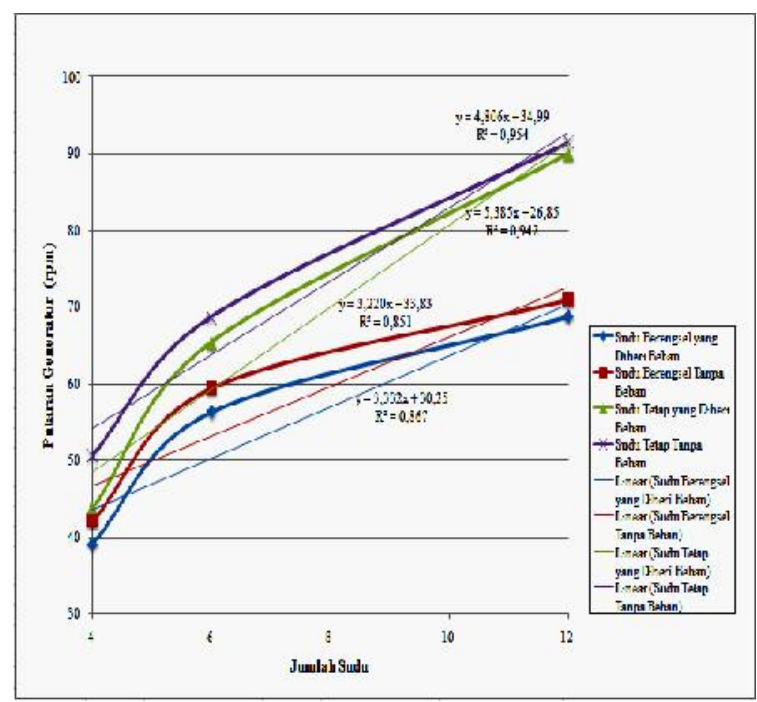

Gambar 7. Grafik perbandingan putaran generator saat divariasikan jumlah sudu dan pergerakan sudu serta pemberian beban pada generator turbin

Semakin banyak jumlah sudu yang mengelilingi runner, maka putaran generator akan semakin tinggi pula. Dan sudu tetap merupakan pergerakan sudu yang mempengaruhi perputaran sudu yang dihasilkan akan lebih tinggi dibandingkan saat gerakan sudu berengsel.

Hal itu terjadi karena perbedaan fungsi energi output air yang keluar melalui celah - celah sudu, setelah menabrak permukaan sudu yang menghadap nosel dan adanya parameter pergerakan sudu. Sudu berengsel menghasilkan putaran generator yang lebih kecil dibandingkan dengan putaran generator saat gerakan sudu tetap. Karena energi output air yang keluar melalui celah - celah sudu lain dibelakang sudu tersebut, berfungsi sebagai pendorong sudu - sudu dibelakang sudu yang sedang menghadap ke nosel dengan posisi menutup agar terbuka dan energi output air tebut dapat keluar ke saluran buang saat parameter pergerakan sudu berengsel. 
Sedangkan saat gerakan sudu tetap, energi output air tadi akan menabrak permukaan sudu lain yang ada di belakang sudu yang menghadap ke nosel dan menyebabkan putaran generator akan semakin cepat dan energi output air tersebut dapat keluar langsung menuju saluran buang. Tanpa adanya halangan dari sudu lain di bagian belakang sudu yang menghadap ke nosel karena, sudu - sudu bagian belakang selalu terbuka. Energi input selanjutnya dapat masuk dengan mudah ke nosel untuk memutar rotor, sehingga putaran generator akan semakin bertambah besar.

Energi output generator merupakan energi listrik yang dihasilkan generator, pembacaannya dilakukan di rangkaian listrik yang ada di sisi sebelah kanan instalasi turbin. Letak generator dan rangkaian listrik, bersebelahan di sisi sebelah kanan instalasi turbin. Hanya agak bawah, letak rangkaian listriknya.

Data tegangan listrik (V) dan arus listrik (I) yang diperoleh saat pengukurannya dengan menggunakan alat ukur AVOmeter di rangkaian listrik yang telah dihubungkan dengan generator yang menghasilkan energi listrik (sumber energi listrik). Ditampilkan pada tabel 2 berikut ini.

Tabel 2. Tegangan listrik (V) dan arus listrik (I) sebagai energi output generator

\begin{tabular}{|c|c|c|c|c|c|c|}
\hline \multirow{2}{*}{ Variasi } & \multicolumn{2}{|c|}{12} & \multicolumn{2}{|c|}{6} & \multicolumn{2}{c|}{4} \\
\cline { 2 - 7 } & $\begin{array}{c}\mathrm{V} \\
\text { (Volt) }\end{array}$ & $\begin{array}{c}\mathrm{I} \\
\text { (Ampere) }\end{array}$ & $\begin{array}{c}\mathrm{V} \\
\text { (Volt) }\end{array}$ & $\begin{array}{c}\mathrm{I} \\
\text { (Ampere) }\end{array}$ & $\begin{array}{c}\mathrm{V} \\
\text { (Volt) }\end{array}$ & $\begin{array}{c}\text { I } \\
\text { Ampere) }\end{array}$ \\
\hline $\begin{array}{c}\text { Sudu } \\
\text { Berengsel }\end{array}$ & 60 & 0,36 & 50 & 0,30 & 40 & 0,22 \\
\hline $\begin{array}{c}\text { Sudu } \\
\text { Tetap }\end{array}$ & 65 & 0,45 & 60 & 0,22 & 50 & 0,25 \\
\hline
\end{tabular}

Energi output generator yang paling besar diperoleh saat jumlah sudu 12 sudu dengan pergerakan sudu tetap. Dengan menggunakan rumus perhitungan tegangan listrik (V) dikalikan dengan arus listrik (I) akan diperoleh ukuran energi listrik yang dihasilkan generator (energi output generator). Berikut ini adalah perhitungan yang digunakan untuk memperoleh besar energi listrik yag dihasilkan generator saat jumlah sudu 12 buah dengan gerakkan sudu berengsel;

$$
\begin{aligned}
\mathrm{E}_{\mathrm{og}} & =\mathrm{V} \mathrm{I} \\
& =60 \text { Volt } 0,36 \text { Ampere } \\
& =21,60 \text { Watt }
\end{aligned}
$$

Hasil perhitungan energi output generator yang menggunakan parameter lain, akan ditampilkan pada tabel 3 berikut ini.

Tabel 3. Energi listrik yang dihasilkan generator (energi output generator)

\begin{tabular}{|l|c|c|c|}
\hline \multirow{3}{*}{ Variasi } & \multicolumn{3}{|c|}{$\begin{array}{c}\text { Energi listrik yang } \\
\text { dihasilkan generator } \\
\left(\mathrm{E}_{\mathrm{og}}\right) \text { (Watt) }\end{array}$} \\
\cline { 2 - 4 } & \multicolumn{2}{|c|}{ Variasi Jumlah Sudu } \\
\cline { 2 - 4 } & 12 & 6 & 4 \\
\hline $\begin{array}{l}\text { Sudu } \\
\text { Berengsel }\end{array}$ & 21,60 & 15,00 & 8,80 \\
\hline Sudu Tetap & 29,25 & 13,20 & 12,50 \\
\hline
\end{tabular}

Berikut ini akan ditampil data - data energi output generator dalam bentuk grafik.

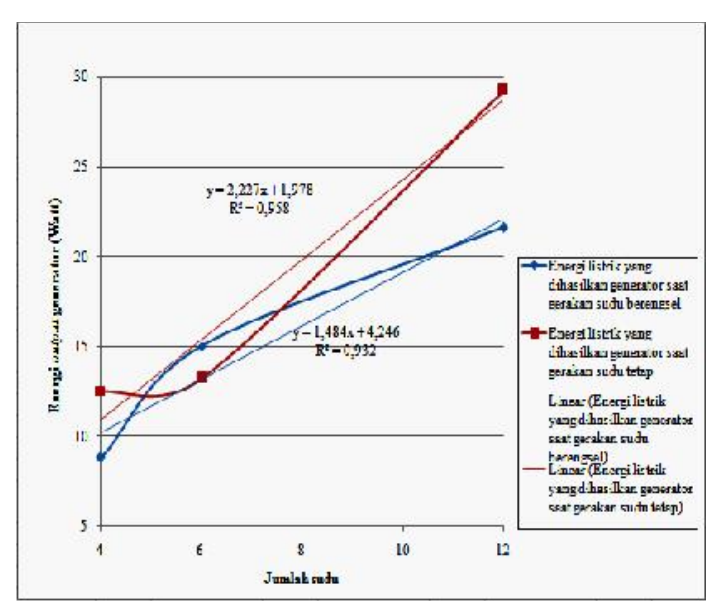

Gambar 8. Grafik energi listrik yang dihasilkan generator (energi output generator)

Di rangkaian listrik yang digunakan sebagai beban untuk energi output generator terdapat diode. Fungsi diode disini adalah merubah arah arus listrik yang dihasilkan generator agar dapat masuk ke rangkaian listrik sebagai sumber energi listrik yang mampu menghidupkan lampu LED yang tersusun secara paralel di rangkaian listrik tersebut. Arus listrik yang dihasilkan generator adalah arus bolak balik (AC) setelah masuk ke rangkaian listrik arus listriknya akan berubah arah menjadi arus searah (DC).

Semakin banyak jumlah sudu yang mengelilingi runner maka energi output generator akan semakin tinggi pula. Untuk parameter pergerakan sudu, sudu tetap adalah parameter pergerakan sudu yang 
menghasilkan energi output lebih tinggi dibandingkan sudu berengsel. Besar energi output generator yang terbesar, sebesar 29 , 25 Watt. Energi output tertinggi ini dihasilkan saat parameter variasi jumlah sudu adalah 12 sudu dengan gerakan sudu tetap.

Energi kinetik input yang diperoleh dari air sebagai fluida penggerak, diukur dengan menggunakan alat ukur tabung pitot. Dari alat ukur tabung pitot diperoleh ketinggian relatif terhadap aliran fluida (Inlet) menuju permukaan sudu turbin pada rotor, yang disimbolkan $\left(h_{i}\right)$.

Tabel 4. Ketinggian relatif terhadap aliran fluida masuk (Inlet) menuju permukaan sudu turbin pada rotor

\begin{tabular}{|c|c|c|c|}
\hline \multirow{2}{*}{ Variasi } & 12 & 6 & 4 \\
\hline & (m) & (m) & (m) \\
\hline $\begin{array}{c}\text { Sudu } \\
\text { Berengsel }\end{array}$ & $1,97 \quad 10^{-2}$ & $1,90 \quad 10^{-2}$ & $1,83 \quad 10^{-2}$ \\
\hline Sudu Tetap & $2,07 \quad 10^{-2}$ & $1,87 \quad 10^{-2}$ & $2,00 \quad 10^{-2}$ \\
\hline
\end{tabular}

Kecepatan dapat diukur dengan menggunakan tabung pitot sebagai alat ukur, dan diperhitungkan dengan menggunakan rumus sebagai berikut;

$$
\mathrm{v}=\sqrt{\frac{2 \times \mathrm{g} \times \rho^{\prime} \times \mathrm{h}}{\rho_{\mathrm{u}}}}
$$

Dimana;

$$
\begin{aligned}
\mathrm{g}= & \text { Gaya gravitasi }\left(9,8 \mathrm{~m} / \mathrm{s}^{2}\right) \\
\mathrm{h}= & \text { Ketinggian relatif terhadap } \\
& \text { suatu referensi }(\mathrm{m}) \\
\rho^{\prime}= & \text { Massa jenis air raksa }\left(13.600 \mathrm{~kg} / \mathrm{m}^{3}\right. \\
\rho_{\mathrm{u}}= & \text { Massa jenis udara }\left(1,2 \mathrm{~kg} / \mathrm{m}^{3}\right)
\end{aligned}
$$

Berikut ini adalah perhitungan kecepatan aliran fluida masuk (Inlet) menuju permukaan sudu turbin pada rotor dengan variasi jumlah sudu sebanyak 12 buah dan pergerakan sudu berengsel.

$$
\begin{aligned}
v & =\sqrt{\frac{2 \times \mathrm{g} \times \rho^{\prime} \times \mathrm{h}_{\mathrm{i}}}{\rho_{\mathrm{u}}}} \\
= & \sqrt{\frac{2 \times 9,8 \mathrm{~m} / \mathrm{s}^{2} \times 13.600 \mathrm{~kg} / \mathrm{m}^{3} \times 1,97 \times 10^{-2} \mathrm{~m}}{1,2 \mathrm{~kg} / \mathrm{m}^{3}}} \\
& =66,15 \mathrm{~m} / \mathrm{s}
\end{aligned}
$$

Besar kecepatan aliran fluida masuk (Inlet) menuju permukaan sudu turbin pada rotor dengan variasi jumlah sudu dan pergerakan sudu lainnya akan ditampilkan pada tabel 5 , berikut ini.

Tabel 5. Kecepatan aliran fluida masuk (Inlet) menuju permukaan sudu turbin pada rotor

\begin{tabular}{|l|c|c|c|}
\hline \multirow{2}{*}{\multicolumn{1}{|c|}{ Variasi }} & \multicolumn{3}{|c|}{$\begin{array}{c}\text { Kecepatan aliran } \\
\text { (m/s) }\end{array}$} \\
\cline { 2 - 4 } & 12 & 6 & 4 \\
\hline Sudu Berengsel & 66,15 & 64,97 & 63,76 \\
\hline Sudu Tetap & 67,81 & 64,45 & 66,65 \\
\hline
\end{tabular}

Kecepatan aliran fluida masuk ke rotor turbin yang maksimum diperoleh saat parameter yang digunakan saat pengujian adalah jumlah sudu yang mengelilingi runner sebanyak 12 sudu dengan gerakan sudu tetap. Besar kecepatan aliran yang maksimal tersebut sebesar $67,81 \mathrm{~m} / \mathrm{s}$.

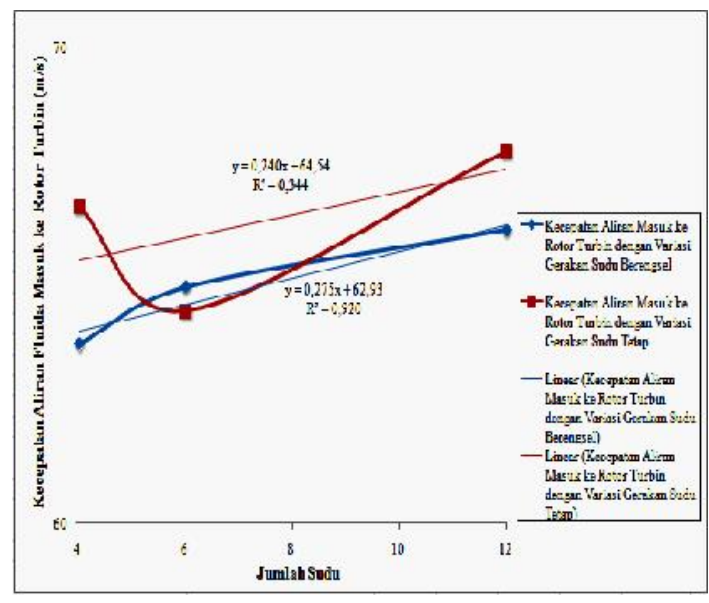

Gambar 9. Grafik perbandingan kecepatan aliran fluida masuk ke rotor turbin dengan variasi jumlah sudu dan pergerakan sudu

Gambar 9 menunjukkan bahwa semakin banyak jumlah sudu, maka energi kinetik input akan semakin besar pula. Bila berdasarkan parameter gerakan sudu, sudu tetap lebih baik dibandingkan sudu berengsel pada penelitian ini. Diakibatkan karena aliran fluida adalah tipe aliran undershot, kemugkinan perkiraan adanya drag force yang mengganggu perputaran rotor terjadi pada instalasi turbin yang menggunakan aliran air tipe aliran overshot.

Kecepatan aliran air yang keluar nosel dan menuju permukaan sudu $\left(\mathrm{v}_{\mathrm{i}}\right)$ memiliki kecepatan yang lebih tinggi dibandingkan kecepatan aliran air yang keluar dari celah - celah sudu pada rotor 
turbin $\left(\mathrm{v}_{\mathrm{O}}\right)$. Karena kecepatan laju aliran energi kinetik inlet ke rotor akan ditransmisikan ke poros turbin menjadi energi mekanik, maka kecepatan laju aliran energi kinetik outlet rotor akan mengecil.

Untuk mengetahui besar energi kinetik input, dilakukan perhitungan laju aliran energi kinetik input. Yang menggunakan laju aliran massa air $(\dot{\mathrm{m}})$ dalam rumus laju aliran energi kinetik input. Laju aliran massa air diperoleh melalui debit air (Q) dikali dengan massa jenis air ( $\rho$ ) sebesar $1000 \mathrm{~kg} / \mathrm{m}^{3}$.

Berikut ini adalah perhitungan laju aliran massa air saat variasi jumlah sudu sebanyak 12 buah dan pergerakan sudu berengsel.

$$
\begin{aligned}
\dot{\mathrm{m}} & =\mathrm{Q} \times \rho \\
& =2,81 \times 10^{-3} \mathrm{~m}^{3} / \mathrm{s} \times 1000 \mathrm{~kg} / \mathrm{m}^{3} \\
& =2,81 \mathrm{~kg} / \mathrm{s}
\end{aligned}
$$

Untuk variasi jumlah sudu dan pergerakan sudu lainnya hasil perhitungan laju aliran massanya akan ditampilkan pada tabel 6 , sebagai berikut ini.

Tabel 6. Laju aliran massa air ( $\mathrm{m}$ )

\begin{tabular}{|l|c|c|c|}
\hline \multirow{2}{*}{ Variasi } & \multicolumn{3}{|c|}{ Laju aliran massa air } \\
\cline { 2 - 4 } & 12 & 6 & 4 \\
\hline $\begin{array}{l}\text { Sudu } \\
\text { Berengsel }\end{array}$ & 2,81 & 3,60 & 3,81 \\
\hline Sudu Tetap & 2,71 & 3,09 & 3,56 \\
\hline
\end{tabular}

Setelah memperoleh besar laju aliran massa air, diperoleh energi kinetik input. Perhitungan energi kinetik input untuk variasi jumlah sudu sebanyak 12 buah dengan gerakan sudu berengsel, sebagai berikut:

$$
\begin{aligned}
\dot{\mathrm{Ek}}_{\mathrm{i}} & =\frac{\dot{\mathrm{m} \times \mathrm{v}_{\mathrm{i}}^{2}}}{2} \\
& =\frac{2,8121 \mathrm{~kg} / \mathrm{s} \times(66,15 \mathrm{~m} / \mathrm{s})^{2}}{2} \\
& =6.152,63 \frac{\mathrm{kgm}}{\mathrm{s}^{3}} \\
& =6.152,63 \mathrm{~J} / \mathrm{s} \\
& =6.152,63 \mathrm{Watt}
\end{aligned}
$$

Untuk perhitungan energi kinetik input dengan variasi jumlah sudu dan pergerakan sudu yang lain, hasil perhitungannya akan ditampilkan pada tabel 7 , berikut ini.

Tabel 7. Energi kinetik input

\begin{tabular}{|c|c|c|c|}
\hline \multirow{2}{*}{ Variasi } & \multicolumn{3}{|c|}{ Eneri kinetik input (Watt) } \\
\cline { 2 - 4 } & 12 & 6 & 4 \\
\hline $\begin{array}{c}\text { Sudu } \\
\text { Berengsel }\end{array}$ & $6.152,63$ & $7.592,71$ & $7.742,23$ \\
\hline Sudu Tetap & $6.245,50$ & $6.413,47$ & $7.918,04$ \\
\hline
\end{tabular}

Dengan demikian, dapat diketahui besar efisiensi sistem pada instalasi turbin hasil penelitian. Berikut ini adalah salah satu bentuk perhitungan efisiensi sistem pada instalasi turbin saat variasi jumlah sudu sebanyak 12 buah dengan gerakan sudu berengsel.

$$
\begin{aligned}
& \eta_{\text {sistem }}=\frac{\mathrm{E}_{\mathrm{og}}}{\frac{1}{2} \times \dot{\mathrm{m}} \times \mathrm{v}_{\mathrm{i}}^{2}} \times 100 \% \\
& =\frac{21,60}{\frac{1}{2} \times 2,8121 \mathrm{~kg} / \mathrm{s} \times(66,15 \mathrm{~m} / \mathrm{s})^{2}} \times 100 \% \\
& =0,35 \%
\end{aligned}
$$

Efisiensi sistem untuk variasi jumlah sudu dan pergerakan sudu yang lainnya akan dimunculkan hasil perhitungannya pada tabel 8.

Tabel 8. Efisiensi sistem dengan variasi jumlah sudu dan pergerakan sudu

\begin{tabular}{|l|c|c|c|}
\hline \multirow{2}{*}{ Variasi } & \multicolumn{3}{|c|}{ Efisiensi Sistem (\%) } \\
\cline { 2 - 4 } & 12 & 6 & 4 \\
\hline Sudu Berengsel & 0,35 & 0,20 & 0,11 \\
\hline Sudu Tetap & 0,47 & 0,21 & 0,16 \\
\hline
\end{tabular}

Semakin banyak jumlah sudu, maka efisiensi sistem akan semakin baik. Jika dibandingkan efisiensi sistem berdasarkan parameter pergerakan sudu, sudu tetap lebih efisien dibandingkan sudu berengsel pada penelitian ini.

Peningkatan energi kinetik input terjadi akibat penurunan jumlah sudu yang mengelilingi rotor. Meski energi kinetik input meningkat, jika energi listrik yang dihasilkan generator (energi output generator) menurun maka efisiensi sistem akan menurun pula. Karena efisiensi sistem diperoleh dari perbandingan energi output generator dengan energi kinetik input. 


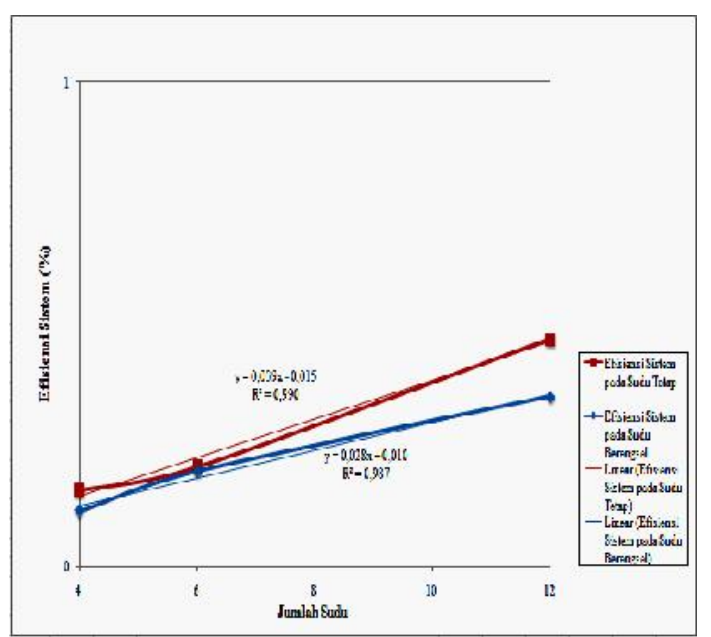

Gambar 10. Grafik perbandingan efisiensi sistem saat divariasikan jumlah sudu dan pergerakan sudu

Pada grafik perbandingan efisiensi sistem antara variasi jumlah sudu dengan gerakan sudu, garis warna merah menunjukkan efisiensi sistem maksimumnya adalah sebesar $0,47 \%$. Dikarenakan, saat variasi gerakan sudu tetap dengan jumlah sudu sebanyak 12 buah menghasilkan daya listrik sebagai energi output generator yang paling besar yaitu sebesar 29,25 Watt. Dan energi kinetik air yang keluar dari nosel sebagai energi kinetik input sebesar 6.152,63 Watt. Sehingga, menunjukkan perbandingan yang paling baik antara daya listrik yang dihasilkan dengan total laju aliran energi kinetik air pada instalasi turbin. Dan perbandingan tersebut yang digunakan sebagai penunjuk besar efisiensi sistem pada instalasi turbin saat pengujian.

\section{KESIMPULAN}

Dari pembahasan dan analisa data dapat ditarik beberapa kesimpulan, antara lain sebagai berikut :

1. Efisiensi sistem yang paling baik diperoleh saat variasi jumlah sudu 12 dengan gerakan sudu tetap. Perbandingan energi output generator dengan energi kinetik input menunjukkan besar efisiensi sistem pada instalasi turbin. Efisiensi sistem saat variasi jumlah sudu 12 buah dan gerakan sudu tetap adalah $0,47 \%$.

2. Putaran generator yang paling banyak terjadi saat variasi jumlah sudu 12 buah dengan pergerakan sudu tetap. Putaran generatornya sebesar $89,9 \mathrm{rpm}$ saat diberi beban dan sebesar $91,5 \mathrm{rpm}$ saat tidak diberi beban.
3. Energi output generator pada instalasi turbin adalah daya listrik yang dihasilkan generator. Pada instalasi turbin yang digunakan saat pengujian, energi output generator yang paling besar diperoleh saat variasi jumlah sudu sebanyak 12 buah dengan gerakan sudu tetap. Dan energi output yang dihasilkan sebesar 29,25 Watt.

4. Jumlah sudu yang mengelilingi poros rotor turbin cross flow zero head mempengaruhi unjuk kerja turbin cross flow zero head. Dapat disimpulkan bahwa semakin banyak jumlah sudu maka efisiensi sistem pada instalasi turbin yang digunakan untuk pengujian ini akan bertambah pula.

5. Pada instalasi turbin yang digunakan, pergerakan sudu tetap adalah pergerakan sudu yang menghasilkan efisiensi sistem lebih tinggi dibandingkan pergerakan sudu berengsel.

Setelah dihubungkan dengan hipotesa penelitan yang memperkirakan gerakan sudu berengsel akan mengurangi terjadinya drag force pada saat instalasi turbin beroperasi dan membuat efisiensi sistemnya menjadi menigkat. Hasil penelitian tidak sesuai dengan yang diperkirakan. Tipe aliran air sebagai fluida kerja yang memutar rotor akan sangat berpengaruh terhadap unjuk kerja turbin. Tipe aliran air yang digunakan pada penelitian ini adalah tipe aliran undershot. Kemungkinan, apa yang diperkirakan pada hipotesa penelitian ini akan berlaku saat tipe aliran air yang digunakan adalah tipe aliran overshot. 


\section{DAFTAR PUSTAKA}

[1] Arismunandar, W., 1982, Penggerak Mula Turbin, Bandung : Penerbit ITB.

[2] Luknanto, D., 2008, Diktat Kuliah Bangunan Tenaga Air, Surabaya : ITS.

[3] Haimerl, L.A., 1960, The Cross Flow Turbine, Jerman Barat.

[4] Arsyad, I.M., 2009, Applikasi Turbin Cross Flow untuk Pembangkit Listrik Mikrohidro di Kalimantan Barat, Jurnal ELKHA, Vol. 1, No. 3., Maret 2009, Universitas Tanjungpura, Pontianak.

[5] Larasakti, A.A., Himran, S. dan Arifin, S.A., 2012 , Pembuatan dan Pengujian Pembangkit Listrik Tenaga Mikrohidro Turbin Banki Daya 200 Watt, Jurnal Mekanikal, Vol. 3, No. 1., Januari 2012, p. 245-253.
[6] Tirono, M., 2012, Pemodelan Turbin Cross Flow untuk Diaplikasikan pada Sumber Air dengan Tinggi Jatuh dan Debit Kecil, Jurnal Neutrino, Vol. 4, No. 2., April 2012, UIN Maliki Malang, Malang.

[7] Sahid, 2012, Kaji Eksperimental Kinerja Turbin Cross Flow Berbasis Konstruksi Silinder (Drum) Poros Vertikal untuk Potensi Arus Sungai, B. 10., Universitas Wahid Hasyim Semarang, Semarang. 